\title{
Why Startups Need Libraries (And Librarians)
}

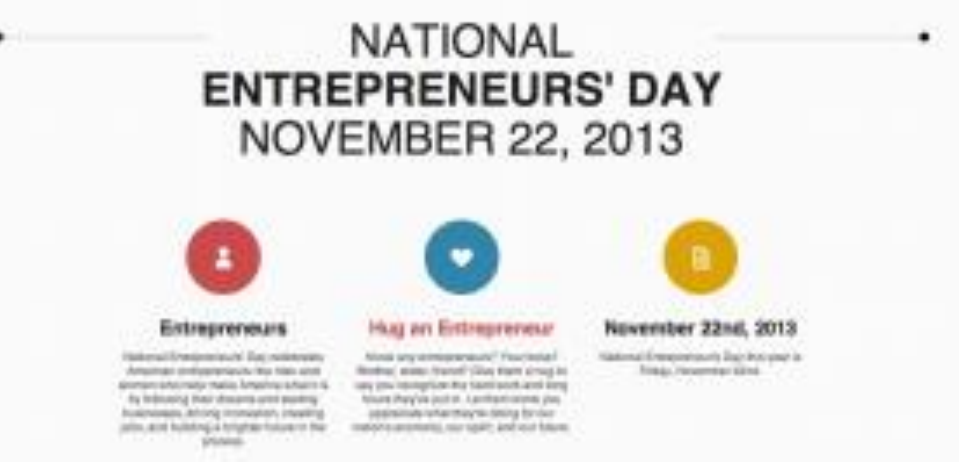

\section{The Startup Buzz}

Tomorrow, the United States will celebrate National Entrepreneurs' Day, which began in 2010 when the Obama administration first proclaimed November as National Entrepreneur Month. Paired a few months later with the 2011 launch of the Startup America initiative, National Entrepreneur Day recognizes, for the first time, the American entrepreneurial spirit as a part of public discourse. In his 2013 proclamation, Obama notes, "Our Nation is strongest when we broaden entrepreneurial opportunity, when more of us can test our ideas in the global marketplace, and when the best innovations can rise to the top;" continuing that the role of universities is to "cultivate hubs of innovation" so that these opportunities, ideas, and innovations might flourish. In doing so, Obama not only acknowledges the need for universities to lay the groundwork for future innovators and entrepreneurs, but also implicitly calls upon the individuals who maintain the operation of these universities, library and information science scholars included, to consider their role in an increasingly entrepreneurial environment on the college campus.

\section{Entrepreneurial Libraries}


While universities have broadly been warming to the idea of becoming hubs of innovation, this opportunity has not yet begun to take shape in many critical sectors of the university, including libraries. This is both a misfortune and a call to action, and was most clearly evidenced in October of this year when the Commerce Department issued a 100-page report titled, "The Innovative and Entrepreneurial University," in which the word library was not once mentioned. This is alarming as the report notes both that, "Over the last two decades, the majority of job creation in the United States has occurred in young, startup companies," and, "Over the last decade, universities have been the largest sector to receive federal research and development (R\&D) grants -receiving nearly \$36 billion from federal agencies in FY2009.” So not only are startup companies the primary source of job creation in the US economy, but universities are also the primary sector that the government invests in to encourage the research and innovation from which startups are born.

The body of the report considers quite extensively the best practices of the most successful universities in using federal funding to become both innovative and entrepreneurial, ranging from promoting student innovation with degree programs; patent clinics; internships; business competitions; and innovative residence halls to supporting faculty research with entrepreneurs in residence and including entrepreneurial activity in the promotion and tenure requirements. Even more ambitious is the successful practice of actively expanding the role of University Technology Transfer Offices, facilitating university collaboration with industry, and engaging with regional and local economic development plans. One might find it intuitive that libraries would be involved with 
many, if not all, of these best practices; and while they might be indirectly, it is significant that the report does not once mention them specifically.

In the face of such exclusion, academic libraries must now call upon themselves to play a direct role in supporting the next generation of entrepreneurs to get their start. And academic librarians must be both cognizant of the needs of budding entrepreneurs and to have themselves the mindset of a startup culture. The primary way in which a library can support entrepreneurship is the development of its space to support innovation. And as a model, they can look to private spaces that are quickly becoming the hubs of innovation that the President encouraged university campuses to develop.

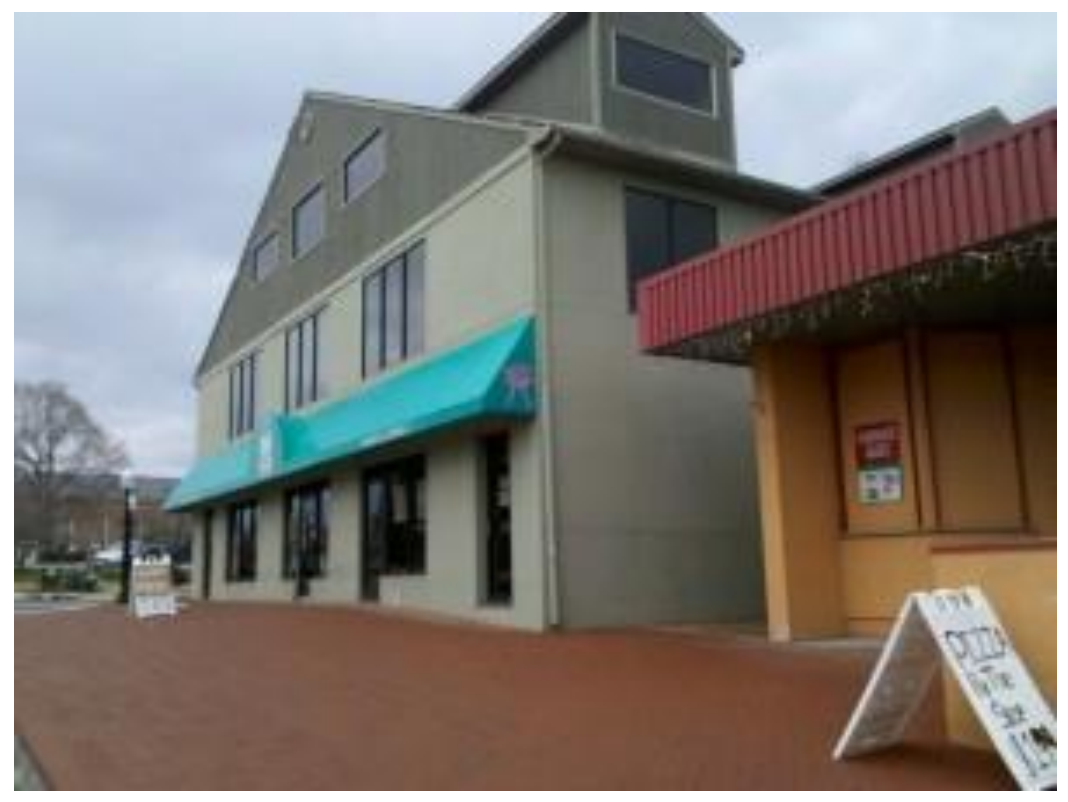

One such example is Techpad, located across the street from the Virginia Tech campus in Blacksburg, Virginia. Techpad is a 6000 square-foot co-working space for creative thinkers, designers, and developers, all working for student-founded startup companies using the space to conduct their business. The concept of co-working space encourages constant communication with individual students, other startups, and Techpad 
advisors, former and current business leaders who guide student and company

development. In their 3-minute introduction video, every one of the Techpad participants interviewed cites collaboration as what makes Techpad both a good environment in which to work and a successful launchpad for startup companies. And perhaps most poignantly, one student even offers that Techpad pulls in students who otherwise would have been unaware of entrepreneurial opportunities located right across the street from their college campus.

Everything that Techpad does, libraries can do in a university-supported, campus setting. And Brian Mathews, the Associate Dean of Learning and Outreach at the Virginia Tech Libraries, has already begun to consider the implications of this in his research. In his white paper, “Think Like a Startup,” Mathews composes a manifesto of sorts for encouraging entrepreneurial spirit in academic libraries. His advice ranges from philosophical to strategic, but embraces throughout the idea of breaking free from the old to try the new. A few key takeaways from Mathew's paper include:

- Not aiming to simply expand services, but solve problems. Mathews believes that the library is a platform, not a place, and that libraries must challenge themselves to invent new solutions to current problems.

- Performing less assessment and focusing more on $R \& D$. This returns to universities receiving the largest amount of funding from the federal government for R\&D. Libraries, as a part of universities, can benefit from this if their focus is on research and development.

- Trying many solutions, maintaining the ones that work, and giving up on the ones that don't. 
- Providing space for usable, feasible, and valuable ideas to incubate, fail, and evolve.

- Remembering that innovation happens in the public space, and is a messy and disruptive process.

- Staking a claim in other parts of scholarly enterprise.

- And finally, embracing the knowledge that entrepreneurialism is not going away. Libraries must learn to incorporate it into their models, while striving to change the profession in doing so.

If libraries want to become a key player in the growing innovative and entrepreneurial university, they need to be willing to embrace these takeaways and become spaces that support the next generation of entrepreneurs.

\section{A Place for Librarians}

But perhaps entrepreneurial library and information science students want to find work beyond the university library. This is not only a possibility, but also an attainable reality. The knowledge and skills that library and information science students acquire in the classroom are exactly those that startup companies need and want in new hires.

In a 2011 article in defense of a PhD in the humanities, Damon Horowitz concludes, "You go into the humanities to pursue your intellectual passion; and it just so happens, as a by-product, that you emerge as a desired commodity for industry." Though specifically referring to the IT sector, on a broader level Horowitz, the in-house philosopher at Google, is examining what it takes to be a desired commodity in a startup economy. He even acknowledges this himself when he references his involvement with a startup called Aardvark, a search engine that defined a query as, "an invitation to a 
human engagement." Horowitz argues that this focus on the human is what made Aardvark a successful startup; and that it was his educational development that allowed the idea to be born at all.

While Horowitz's is writing to technologists whom he would like to convert to humanists through humanity $\mathrm{PhD}$ programs, his argument could be equally, if not better, made for pursuing a degree in library and information science. When it comes to employability in IT startups, Horowitz believes that it is a human-centered approach that makes one exceptional. And this is at the very core of the library and information science degree. Take for example, the final portfolio of graduates of the Pratt Institute School of Information and Library Science. Of five that a student must demonstrate having achieved throughout the program, one is a user-centered focus in which they "apply concepts related to use and users of information and user needs and perspectives." This is precisely what Horowitz desires new hires in the startup world demonstrate, and illustrates that librarians, as content creators with a user-centered focus, are not only what the startup world needs, but also what it wants.

In addition to user-centered focus, the four remaining learning objectives of a Pratt Institute information and library science student are carrying-out and applying research; demonstrating excellent communication skills and creating and conveying content; using information technology and digital tools effectively; and performing within the framework of professional practice. Together, these five learning objectives create the ideal new hire for startup companies. 


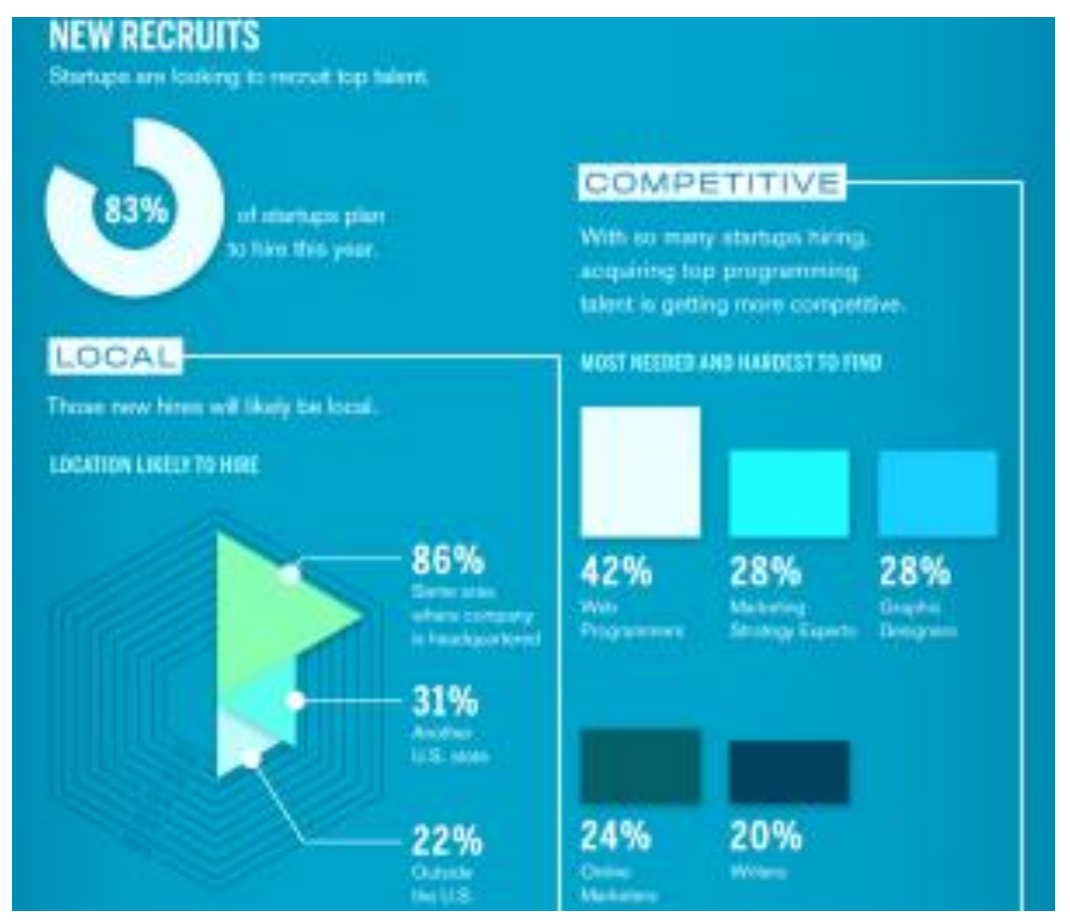

Demographically speaking, who works at startups is quite diverse. In 2012, UP Global, a nonprofit that works with and researches startup companies, released an infographic featuring startup company profiles and new hires. Regarding expanding and location, more than $75 \%$ of the startups surveyed were looking to hire in the next 12 months and were looking to do so locally. But more importantly, the positions that they listed as both most difficult and most needed to fill were positions that library and information science graduates easily fit.

The idea that library and information science students could continue on after graduation to work for a startup company is further supported by a 2011 blog post on the Syracuse School of Information Studies website. In her post, Mia Breitkopf, a student at the time, explored non-library jobs for library and information science students. Many of the jobs she listed, including project manager, analytics manager, information resource specialist, and technology coordinator, happened to be positions listed by startup companies. 
Even today, one need not look any farther than a few startup companies' websites and hiring pages to see how the skills that an information and library science student develops in the classroom are those that startups want. The tech startup, bit.ly, is currently looking to hire a business who is, "resourceful and metrics driven, an expert at building knowledge-based product value from limited information, and is eager to learn.’Refinery29, a fashion and style website, has a listing for a marketing coordinator whose day-to-day responsibilities include, "analyzing performance of partner and influencer initiatives; working closely with the social media team to ideate on growing social channels; experimenting with new and alternative ways to leverage social media activities; and monitoring trends, strategies and best practices in the market." And online retailer, Birchbox, is searching for a brand campaign analyst to, "gather data sets from various sources and identify data trends to include in campaigns, and serve as data expert for brand partners to inform new campaign designs.”

Returning to the Pratt Institute library and information student, it becomes clear that she will have the skill set necessary to fulfill any of these roles upon completion of her degree, through her fulfillment of the school's established learning objectives of research, communication, user-centered focus, technology, and library and information science practice.

\section{Going Forward}

The future, as indicated by present trends, shows that the startup company is the way in which the economy is building itself back. And startups need libraries and librarians. The question now is how libraries and librarians will answer this call, and in doing so, demonstrate that they need startups as much as startups need them. If academic 
libraries embrace the need to break from the old and try something new, they can become the central hub of innovation at increasingly entrepreneurial college campuses. And if entrepreneurial library and information science students embrace the learning objectives of their programs, they can become the ideal new hire for any number of emerging innovative startup companies. In this sense, the future is bright for library and information science as we usher in National Entrepreneur's Day 2013. 